\title{
Correction to: Business Model Management
}

Correction to:

B. W. Wirtz, Business Model Management,

A correction was unfortunately exchanged during the proofing and correction 8 process. The version supplied here has been updated.

Page 67

Deleted Chapter 5.1 here, and inserted as in Chapter 9.1

Page 144, fourth line from bottom

Inserted: (content based on Vaile, Grether, and Cox 1952 and Berman 1996). 13

Page 145, figure caption

Deleted source Berman 1999, and inserted: Wirtz (2010a, 2011, 2018a) 15

Page 159, third line from bottom

Replaced content from Chapter 5.1

Page 163, table caption

Inserted: Source: Wirtz (2010a, 2011, 2018a) 19

$\begin{array}{ll}\text { Page 164, figure caption } & 20\end{array}$

Inserted: Source: Wirtz (2010a, 2011, 2018a) 21

Page $165 \quad 22$

Deleted content up to line 15, and replaced with Chapter 5.1 23

The updated online versions of the chapters can be found at https://doi.org/10.1007/978-3-030-48017-2_5 https://doi.org/10.1007/978-3-030-48017-2_8 https://doi.org/10.1007/978-3-030-48017-2_9 https://doi.org/10.1007/978-3-030-48017-2_14 https://doi.org/10.1007/978-3-030-48017-2_15 https://doi.org/10.1007/978-3-030-48017-2_16

(C) The Editor(s) (if applicable) and The Author(s), under exclusive licence to Springer Nature Switzerland AG 2020

B. W. Wirtz, Business Model Management, Springer Texts in Business and Economics, https://doi.org/10.1007/978-3-030-48017-2_22 
$24 \quad$ Page 166

25 Deleted "the content provided by Zott and Amit $(2007,2010)$." and inserted "this 26 approach."

$27 \quad$ Page 230

28 Inserted: Source: Wirtz (2010a, 2011, 2018a)

$29 \quad$ Page 238

30 Inserted: Source: Wirtz (2010a, 2011, 2018a)

$31 \quad$ Page 254

32 Inserted: Source: Wirtz (2010a, 2011, 2018a) 